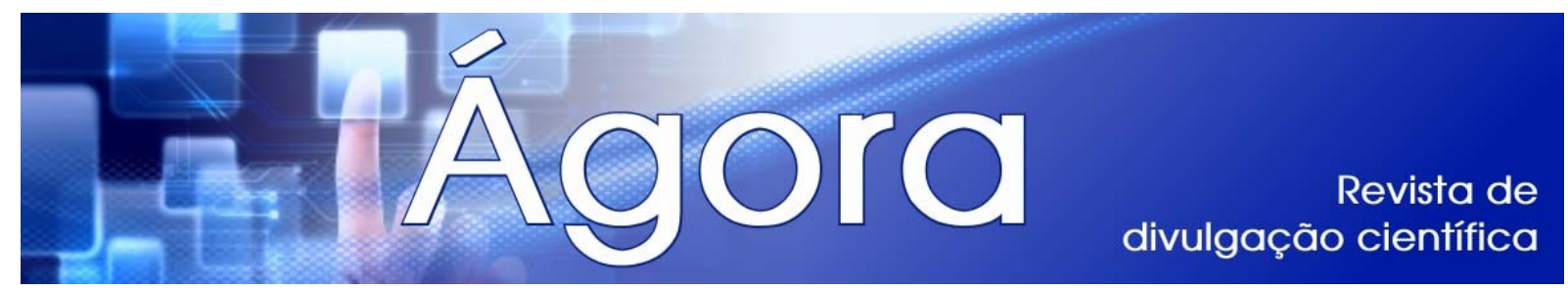

\title{
SUSTENTABILIDADE ECONÔMICA E AMBIENTAL DA ATIVIDADE AVÍCOLA EM PROPRIEDADES DO MUNICÍPIO DE ITÁ-SC ${ }^{1}$
}

\author{
Francieli Dalle Laste Valmorbida ${ }^{2}$ \\ Leonilda Maria Funez ${ }^{3}$
}

\begin{abstract}
RESUMO: Objetivou-se, por meio deste trabalho realizar um levantamento da situação econômica e ambiental das propriedades avícolas do município de Itá Santa Catarina. A pesquisa foi realizada com sete agricultores do município de Itá através da aplicação de um questionário com perguntas mistas. Os resultados indicaram que a atividade predominante é a avicultura, sendo a renda familiar dos proprietários satisfatória. No entanto faltam informações quanto à utilização de alternativas que promovam a sustentabilidade ambiental nas propriedades. Pode-se afirmar que as propriedades estão bem estruturadas, porém há necessidade de informações acerca de projetos que visam a sustentabilidade.
\end{abstract}

Palavras chaves: Avicultura; Meio ambiente; Sustentabilidade.

ABSTRACT: The aim of this work was to carry out a survey of the economic and environmental situation of the poultry properties of the municipality of Itá in Santa Catarina State. The research was carried out with seven farmers of the municipality of Itá by applying a questionnaire with mixed. The results indicated that the predominant activity is poultry, and the family income of the owners is satisfactory. However, there is a lack of information about the use of alternative farming practices that promote the environmental sustainability of the properties. We can say that the properties are well organized, but there is need of information about projects aimed at sustainability.

Key words: poultry, environment, sustainability

\footnotetext{
${ }^{1}$ Órgão financiador do projeto: FUMDES

${ }^{2}$ Acadêmica do Curso de Ciências Biológicas da Fundação Universidade do Contestado. Endereço:

Linha São Paulo, interior. CEP: 89760-000, Itá- SC. E-mail: francieli dallelaste@hotmail.com

${ }^{3}$ Bióloga e professora da Fundação Universidade do Contestado. Endereço: Rua Aimrés, 241. Bairro: Redim. CEP: 8970-000, Concórdia- SC. E-mail: leonilda.funez@yahoo.com.br
}

Ágora: R. Divulg. Cient., v. 18, n. 2, p. 193-201, dez. 2011 (ISSN 2237-9010) 


\section{INTRODUÇÃO}

A atividade agropecuária tem importância, principalmente nos aspectos sociais, econômicos e ambientais. Porém, esta atividade gera por um lado riqueza e por outro, importante degradação ambiental, que deve ser controlada para que as futuras gerações não sofram com impactos negativos decorrentes desta atividade.

O setor agropecuário na região oeste de Santa Catarina é formado basicamente por pequenas propriedades que estão integradas com o setor agroindustrial. Além disso, a produção de suínos, aves e milho abastece mercados internacionais e nacionais, sendo que em 1996 a mesorregião gerou $56 \%$ do valor total de produção agropecuária do estado (SECRETARIA, 1997).

A região oeste possui um relevo bastante acidentado e apenas $20 \%$ do solo pode ser utilizado para as atividades agrícolas sem restrição. No entanto, apesar das restrições, a região é considerada o "celeiro" do estado, pois sozinho produz $74 \%$ do milho, $67 \%$ da carne suína e $82 \%$ da carne de aves (SECRETARIA, 1997).

Atualmente, uma das maiores preocupações está na necessidade de implantar projetos que visam a sustentabilidade econômica e ambiental das propriedades rurais, para que desta forma, o trabalhador rural permaneça no campo, realizando sua função que é de extrema importância para o desenvolvimento sócioeconômico.

Uma propriedade rural pode ser altamente produtiva sem agredir o meio ambiente, quando sua utilização é feita de forma racional e adequada, visando equilíbrio ecológico e a garantia da saúde, da qualidade de vida e do bem-estar social e econômico dos proprietários e daqueles que nela trabalham (VIEGAS, 2009).

A preocupação em planejar ambientalmente as propriedades rurais tem se destacado muito atualmente, buscando uma melhoria de sua produção agropecuária, preservando os recursos hídricos para a demanda da propriedade $\mathrm{e}$ manejando adequadamente os solos, garantindo desta forma a sustentabilidade da propriedade e a preservação dos recursos naturais existentes.

O êxodo rural também é outro fator preocupante, visto que o abandono dos campos para a ocupação das cidades tem reflexos negativos e produzirá em curto prazo, problemas muito mais graves, como o aumento da população urbana e a 
diminuição da geração de ICMS (Imposto sobre circulação de mercadorias e prestação de serviços) e IPI (Imposto sobre produtos industrializados), causando impactos econômicos negativos ao município.

Diante disso, realizou-se um levantamento de dados através de um questionário com os avicultores do município de Itá no sentido de investigar as condições de sustentabilidade econômica e ambiental da atividade avícola em suas propriedades.

\section{MATERIAL E MÉTODOS}

O presente estudo foi realizado com a participação dos proprietários dos estabelecimentos avícolas do município de Itá, Santa Catarina. Essas propriedades, predominantemente são de agricultura familiar.

Os agricultores trabalham com avicultura de corte e alguns desenvolvem também outras atividades na propriedade.

O município de Itá possui 63 propriedades com produção de aves de corte (EPAGRI, 2003), sendo que a amostra da população pesquisada foi determinada pela amostragem proporcional estratificada, com $10 \%$ do total da população existente, totalizando sete agricultores.

A escolha desses sete estabelecimentos dos 63 existentes foi realizada pela amostragem casual ou aleatória.

Os dados foram coletados por meio da aplicação de um questionário com perguntas mistas, sendo 14 perguntas fechadas e 12 abertas, totalizando 26 perguntas elaboradas pela pesquisadora.

A pesquisadora se deslocou para a residência de cada propriedade selecionada na amostra coletando desta forma os dados com o responsável de cada propriedade para a análise e elaboração conclusão da pesquisa.

Além disso, seguiram-se as normas regulamentadoras da resolução 196/96 do Conselho Nacional de Saúde, que regulamenta a pesquisa envolvendo seres humanos, respeitando-se os aspectos éticos, mantendo o sigilo e anonimato das informações obtidas bem como qualquer informação que pudesse identificar os participantes da pesquisa. 
Os participantes assinaram o TCLE - Termo de Consentimento Livre Esclarecido, sendo que eles poderiam interromper a pesquisa no momento que desejassem. É importante ressaltar que o projeto foi aprovado pelo Comitê de ética em pesquisa sob o parecer consubstanciado número 329/2010

\section{RESULTADOS E DISCUSSÕES}

Verificou-se que a atividade avícola é a atividade agropecuária predominante nas propriedades pesquisadas. Além da avicultura outras atividades são desenvolvidas nas propriedades, como: produção de bovinos de leite (6 propriedades), plantação de eucalipto (4), apicultura (1) e produção de bovinos de corte (1). De Freitas (2009) destaca que desde muito tempo a agropecuária desempenha um papel relevante na economia nacional, pois foi uma das primeiras atividades econômicas desenvolvidas no país.

O estado de Santa Catarina apresenta grande diversidade produtiva entre suas regiões, as quais tendem a uma especialização da produção, cada vez mais definida, destacando-se a região oeste, que em 1996 gerou 56\% do valor total da produção agropecuária estadual (SECRETARIA, 1997).

Já, a produção de frangos de corte no Brasil desenvolveu-se a partir do final da década de 1950, na região sudeste, principalmente em São Paulo. No entanto, foi na década de 70 que esta atividade se deslocou para a região sul. A exportação vem crescendo neste setor ao mesmo tempo em que no mercado consumidor interno, o brasileiro tem mudado o hábito de consumo de carnes, passando de um país consumidor de carne bovina para consumidor da carne de frango (SARCINELLI; VENTURINI; SILVA, 2007).

O crescimento da agropecuária no oeste de Santa Catarina, em especial o aumento da produção de aves resultou na expansão do mercado interno e do avanço nas exportações da carne, refletindo a modernização tecnológica neste setor, fato semelhante que ocorreu com a produção de suínos, na qual houve expansões quantitativas e melhoras qualitativas, através da introdução de raças amis produtivas (SECRETARIA, 1997).

Levando em consideração de que o preceito constitucional estabelece que um salário mínimo deva suprir as despesas básicas de um trabalhador e sua família, o 
Departamento Intersindical de Estatística e Estudos Socioeconômicos (DIEESE) estabeleceu em maio de 2011 que o salário mínimo eficaz para que o brasileiro pudesse suprir suas necessidades mensais de saúde, educação, alimentação, lazer, transportes, vestuário e higiene seriam de 2.293,31 reais (VICENTE, 2011).

Ao analisar a situação econômica das famílias que residem nestas propriedades, afirma-se que a renda familiar varia de 2000 a 10000 reais mensais. Isso demonstra que em apenas duas famílias o salário mensal está um pouco abaixo do necessário para suprir as necessidades básicas (2000 reais), por este motivo, pode-se afirmar que o restante das famílias possui uma renda mensal satisfatória.

Figura 1 - Renda familiar mensal dos proprietários avícolas do município de Itá-SC

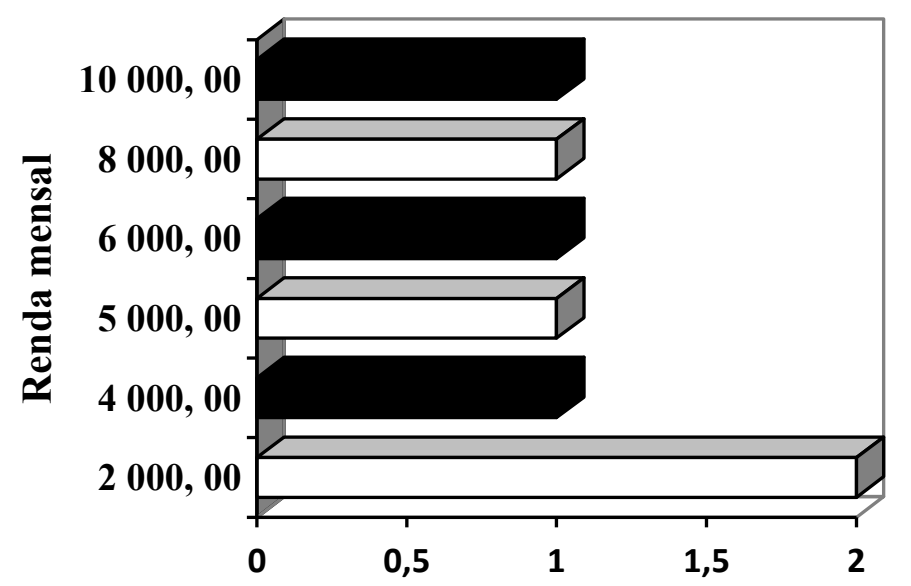

Quantidade de proprietários

Em relação a existência de cisternas nas propriedades, constatou-se que ainda o uso desta forma para armazenamento e utilização da água das chuvas se dá em poucas propriedades. Grings e de Oliveira (2008) ressaltam que a água é um recurso natural limitado e que o elevado consumo deste recurso na produção agropecuária intensiva tem reduzido sua disponibilidade (Figura 2).

Os proprietários que possuem cisternas em suas propriedades relataram nos questionários que é uma alternativa viável, pois pode-se fazer o aproveitamento de água. Grings e de Oliveira (2008) destacam que a utilização de cisternas é uma 
opção que auxilia para o atendimento da demanda de água nas propriedades em períodos de estiagem, quando ocorre diminuição da vazão de água nas fontes.

Figura 2- Existência de cisternas nas propriedades avícolas do município de Itá-SC

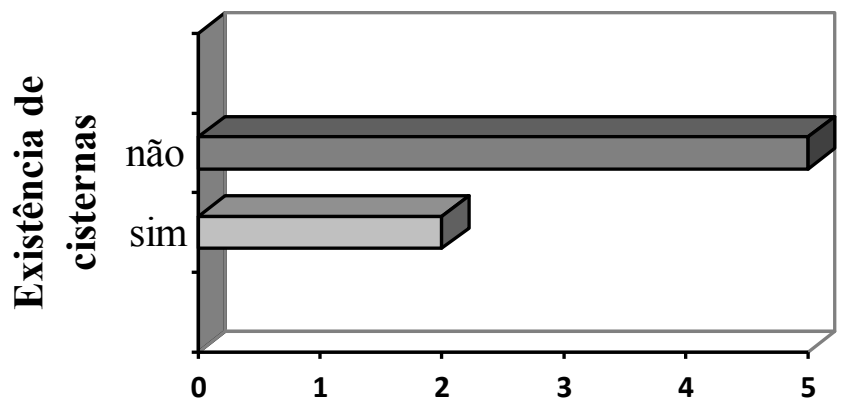

Quantidade de propriedades

Dos que não possuem cisterna na propriedade apenas um proprietário relata não ter interesse em implantar uma cisterna, pelo fato de que na propriedade não há escassez deste recurso até o momento. Os outros quatro proprietários relatam que possuem interesse em implantar, sendo que o proprietário 1 destacou que é importante para armazenar água em épocas de seca e economizar água das fontes, o proprietário 2 destacou que estaria usando recursos naturais e não estaria agredindo a natureza e os proprietários 3 e 4 relataram que é uma solução viável para a falta de água.

Quanto às dificuldades encontradas nas propriedades para implantação de cisternas, a maioria dos questionados relata a dificuldade financeira, pelo fato dessa tecnologia possuir um custo elevado. É importante destacar que o município de Itá sofre com estiagens no período mais seco do ano, tanto que no início de 2012 o município decretou situação de emergência pela falta de água (RBS, 2012).

Em nenhuma das propriedades há biodigestor. Porém, um fato que merece destaque é que somente um dos proprietários tem conhecimento da importância deste equipamento na propriedade além de ter interesse em investir em um biodigestor. Ainda destaca que o biodigestor é importante por produzir energia limpa e dar um destino para os dejetos. Relata que não sente dificuldades em implantar este equipamento e que só irá ampliar a infraestrutura da propriedade e implantar posteriormente esta tecnologia. 
Palhares (2009) destaca que o aumento da produção de frangos de corte nos últimos anos tem levado a produção em grande escala de cama de aviário. Tendo em vista este desafio, a biodigestão ou digestão anaeróbia se mostra como uma alternativa para o tratamento desta cama. Deganutti et al., (2002) afirma que a ideia de produção de biogás nas propriedades rurais pode proporcionar maior conforto nas propriedades por permitir a disposição de um combustível barato e prático que pode ser utilizado tanto na iluminação como também para acionar pequenos motores.

Em todas as propriedades, a atividade avícola possui licenciamento ambiental. Segundo a FATMA (2010) para a atividade avícola estar em acordo com a legislação ambiental, o proprietário deve apresentar três documentos indispensáveis: a licença ambiental prévia que declara a possibilidade do projeto avícola ser executado, a licença ambiental de instalação que autoriza a implantação da atividade ou instalação de qualquer equipamento baseado no projeto final e a licença ambiental de operação que autoriza o funcionamento da atividade com base em vistoria ou qualquer meio técnico de verificação.

Quanto aos interesses dos proprietários em realizar um curso de administração rural 5 proprietários assinalaram (sim) e 2 proprietários (não).

Apesar de $28,57 \%$ da população pesquisada não possuir interesse em fazer um curso de administração rural, todos relataram que este curso é importante pelo fato de adquirir conhecimentos que auxiliam na administração das propriedades.

Apesar de todos avanços tecnológicos, a agropecuária ainda depende de recursos naturais e a degradação desses recursos podem inviabilizar os atuais sistemas de produção além de comprometer o uso para as futuras gerações (MENEGETTI, 2004).

No entanto, pelas características que a agricultura familiar apresenta, a democratização do acesso aos recursos naturais é uma necessidade social e um fator de melhor gestão, conservação dos recursos naturais, além de melhorar a gestão econômica do ambiente sempre dentro de uma perspectiva de sustentabilidade (MENEGETTI, 2004).

É importante que para que a sustentabilidade se efetive, esta deve fazer parte da concepção global de desenvolvimento, das políticas, sendo desta forma uma preocupação de todos segmentos (MENEGETTI, 2004). 


\section{CONCLUSÕES E CONSIDERAÇÕES FINAIS}

Com base na pesquisa desenvolvida, pode-se afirmar que as propriedades estão bem estruturadas, porém faltam informações em relação aos projetos que visam a sustentabilidade econômica e ambiental. Cavalcanti (2002) destaca que desenvolvimento sustentável significa reconciliar o desenvolvimento econômico com a necessidade de preservar o meio ambiente, por esse motivo pode-se afirmar que a Natureza é a base necessária e indispensável para a economia, bem como para a vida das gerações presentes e futuras.

Há a necessidade de novas pesquisas na região além da implantação de projetos que enfatizam a sustentabilidade dessas propriedades, que são importantes para o desenvolvimento do município e de toda a região.

\section{REFERÊNCIAS}

CAVALCANTI, Clóvis (Org). Meio ambiente, desenvolvimento sustentável e políticas públicas. São Paulo: Cortez. Recife: Fundação Joaquin Nabuco. 4.ed. 2002

FREITAS, Eduardo. A importância da agropecuária brasileira. Disponível em: $<$ http://www.brasilescola.com/brasil/a-importancia-agropecuaria-brasileira.htm>. Acesso em: 20 maio 2009.

DEGANUTTI, Roberto. et al. Biodigestores rurais: modelo indiano, chinês e batelada. Departamento de Artes e Representação Gráfica FAAC- Faculdade de Arquitetura, Artes e Comunicação, UNESP - Universidade Estadual Paulista Julio de Mesquita. Disponível em: <http://www.seeds.usp.br/pir/arquivos/congressos/ AGRENER2002/pdf/0004.pdf.>Acesso em 15 dez. 2009

EPAGRI. Levantamento agropecuário de Santa Catarina 2002-2003. Disponível em: <http://cepa.epagri.sc.gov.br/Dados_do_LAC/tabelas/modulo2/aves\%20\%20municipio.pdf>. Acesso em: 8 abr. 2010

FATMA. Licença Ambiental Prévia. Disponível em: <http://www.fatma.sc.gov.br/ index.php?option=com_content\&task=view\&id=50\&ltemid=116\#LAP>. Acesso em: 30 mar. 2010.

GRINGS, Vitor Hugo; de OLIVEIRA, Paulo Armando. Cisternas para armazenamento de água da chuva. Embrapa suínos e aves, 2008. Disponível em:

$<\mathrm{http}: / / \mathrm{www}$.google.com.br/\#hl=ptBR\&source=hp\&q=cisternas+para+armazenament $o+d e+\%$ C3\%A1gua $+d a+c h u v a \& a q=f \& a q i=\& a q \mid=\& o q=\& g s \_r f a i=\& f p=143 f f 5 b f 8652891$ a>. Acesso em 25 jun. 2010 
MENEGETTI, Gilmar Antônio. Desenvolvimento, sustentabilidade e agricultura familiar. 2004. Disponível em: <http://www.emater.tche.br/site/br/arquivos/servicos/ biblioteca/digital/art18.pdf> Acesso em: 31 jun. 2012

PALHARES, Julio Cesar Pascale. Uso de biodigestores para tratamento da cama de frango: conceitos importantes para a produção de biogás. Disponível em: $<$ http://docs.google.com/viewer?a=v\&q=cache:kidXUi9Ng0AJ:www.cnpsa.embrapa.b r/down.php\%3Ftipo\%3Dartigos\%26cod_artigo\%3D219+biodigestores+com+cama+d e+avi\%C3\%A1 rio\&hl=pt-BR\&gl=br\&pid=bl\&srcid=ADGEEShXjodnbfe0kfNCOOIX IC675Jzdt6HYQhFsX8Vnii4_rsQ_SFEPNGsgs10vN4MGubadWt3nSbuQWtU3fJVLJ 18DxEobosSKG6m8IAuIMmleTGpTOPTD1yVXJ8hHMF4sIC-

zy59\&sig=AHIEtbSDokQZQhIXq89ZtShSSCB578leNQ> Acesso em: 20 dez. 2009

RBS. Estiagem. Disponível em:<http://wp.clicrbs.com.br/chapeco/tag/estiagem/ page/5/> Acesso em: 31 jun. 2012

SARCINELLI, Miryelle Freire; VENTURINI, Katiane Silva; da SILVA, Luís César. Produção de Frango de Corte. Universidade Federal do Espírito Santo - UFES, 2007. Disponível em:<http://www.agais.com/telomc/b00107_carne_ frangodecorte.pdf.> Acesso em: 15 jan. 2010.

SECRETARIA de Estado do Desenvolvimento Rural e da Agricultura. Síntese anual da agricultura de Santa Catarina. v.1. Florianópolis: Instituto Cepa SC, 1997.

VICENTE, Alberto. Dieese: salário mínimo necessário para suprir as necessidades das famílias brasileiras. 2011. Disponível em:<http://www.salariominimo.net/2011/ 06/06/dieese-salario-minimo-necessario-para-suprir-as-necessidades-das-familiasbrasileiras-maio-de-2011/> Acesso em: 31 jun. 2012

VIEGAS, Alan Veiga. Manual do produtor rural: propriedade rural sustentável. Disponível em:< http://www.Ambientebrasil.com.br/documentos/ propriedade_rural_sustentável_Alan_Viegas.pdf.> Acesso em: 12 jul. 2009 